\title{
Correction to: Toothpaste and mouthwash inactivate $99.9 \%$ of the virus that causes COVID-19
}

The original product news item can be found online at: https://doi.org/10.1038/s41415-020-2476-8.

Author's correction note:

Dental products and services Br Dent J2020; 229: 753.

An incorrect version of this product news item was sent to the Journal in error and published.

The correct text is as follows.

Laboratory studies show that toothpastes containing zinc or stannous and mouthwash formulas with cetylpyridinium chloride (CPC) neutralise the virus that causes COVID-19 by 99.9\%. The studies are part of a Colgate research programme that includes clinical studies among infected people to assess the efficacy of oral care products in reducing the amount of the virus in the mouth, potentially slowing the transmission of the COVID-19 virus.

In the laboratory studies - the first to include toothpaste - Colgate Total and Meridol toothpastes neutralised $99.9 \%$ of the virus after two minutes of contact. Colgate Plax and Colgate Total mouthwashes were similarly effective after 30 seconds. The studies, completed in October, were conducted in partnership with Rutgers New Jersey Medical School's (NJMS) Public Health Research Institute and Regional Biosafety Laboratories.

The results suggest that some toothpastes and mouthwashes may help reduce the spread of SARS-CoV-2, the virus that causes COVID-19, by temporarily reducing the amount of virus in the mouth. The virus spreads through respiratory droplets or small particles produced when an infected person coughs, sneezes, sings, talks, or breathes, according to the US Centers for Disease Control and Prevention.

Concurrent to the laboratory study, Colgate sponsored a clinical study involving some 50 hospitalised subjects with COVID-19. This study demonstrated the ability of Colgate Total (with
CPC and zinc), Colgate Peroxyl, and Colgate PerioGard mouthwashes to substantially reduce the amount of the virus in the mouth temporarily. The researchers plan to share their findings in December. Additional Colgate-supported clinical research studies on toothpaste and mouthwashes are in early stages at Rutgers, the Albert Einstein Institute in Sao Paulo, Brazil, and at the University of North Carolina at Chapel Hill Adams School of Dentistry, with some 260 people with COVID-19 participating in these studies.

As the world's \#1 trusted dental expert, Colgate is committed to leading in science and to ensuring that its products address health challenges and meet consumers' needs. For more information about the effects of oral hygiene on overall health and additional insights on mask mouth and other topics, visit www.colgate.com.

\section{Award-winning bonding}

One Coat 7 Universal is an awardwinning bonding agent from COLTENE.

It can be used with self-etch, selective-etch and total-etch techniques and it will adhere to all types of surfaces - all this in one easyto-apply product.

Clinicians around the world have relied on it for years; they

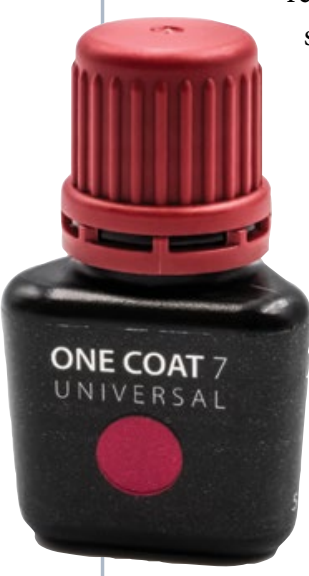
say: 'viscosity is good', 'I like that it's antibacterial' and 'one drop goes a long way'.

One Coat 7 also offers outstanding strength and marginal sealing. It is a proven, light-curing system that will make any workflow more efficient and better value.

For upgraded outcomes, add One Coat 7 Universal to your restorative kit. For more on COLTENE, visit www. coltene.com,email info.uk@coltene. com or call 08002545115.

\section{Helping to optimise your implant therapies}

Available from J\&S Davis, LM Implant Misura MR instruments support optimal implant positioning.

When the first spiral drill is positioned correctly, there will be the correct amount of bone between implant and tooth, helping to guarantee a long-lasting, stable result.

LM Dental is renowned for developing for dentists who want successful clinical outcomes every time. With Implant Misura MR instruments, function and aesthetics are respected equally.

In five sizes, with each diameter represented by a different colour, selection

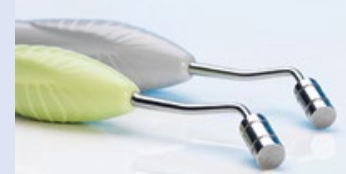

of the right one is easy.

Choose LM's Implant Misura MR instruments for better workflows - contact J\&S today.

Find out more today by visiting www. js-davis.co.uk, calling 01438747344 or emailing jsdsales@js-davis.co.uk.

\section{Swift antibody test}

The ability to quickly and effectively screen your workforce for COVID-19 can enable better informed decisionmaking in getting dental teams back to work safely.

That's why the BioSURE COVID-19 Antibody Rapid Test is a true game changer for dental professionals seeking to differentiate between symptoms of COVID-19 and those of the common cold or flu. This is a single-use, in vitro diagnostic test for detecting COVID-19 antibodies in human blood - users receive results in just ten minutes based on a finger prick of blood.

The BioSURE COVID-19 Triple Antibody Rapid Test comes in a box - priced at $£ 750$ excluding VAT - that contains sufficient product for 25 tests. Order now by calling 01480 862084, email info@curaprox.co.uk or visit www.curaprox.co.uk. 